\title{
A paisagem da Baía de Guanabara através do filme Luz Del Fuego
}

\section{Guanabara`s Bay landscape through the Luz del Fuego's film}

\author{
OLIVEIRA, Bárbara Boy \\ ${ }^{1}$ Programa de Pós-Graduação em Urbanismo, Faculdade de Arquitetura e Urbanismo, Universidade Federal do Rio de \\ Janeiro, Rio de Janeiro, Brasil. barbaraboy57@gmail.com
}

ORCID ID: 0000-0001-8559-3017

Recebido em 27/01/2020 Aceito em 12/02/2020

\begin{abstract}
Resumo
O trabalho discute a paisagem da Baía de Guanabara a partir do filme Luz del Fuego (1982), de David Neves. Partindo da compreensão que a Baía conforma um espaço de memória coletiva que não se dá apenas no tempo passado, mas também no tempo presente, buscamos compreender a atual relação da população fluminense com a Baía. Denis Cosgrove (1989) nos auxilia, identificando múltiplos tipos de paisagens simbólicas, dentro delas: paisagem da cultura dominante e paisagem alternativa. O filme analisado narra a história da dançarina Dora Vivacqua, importante mulher para a libertação feminina no Rio de Janeiro. E possui um olhar particular sobre a Baía, moradia e cenário da morte da protagonista. Durante a narrativa fílmica é necessário olhar não apenas sobre a ótica da paisagem da cultura dominante, mas também sobre a paisagem alternativa, descrita por Cosgrove, como também um problema de gênero, onde muitas vezes existe o apagamento de narrativas femininas. As mulheres fazem parte da cultura excluída da paisagem pública, já que o uso da paisagem pela mulher por muito tempo se deu pela paisagem doméstica. O que Luz del Fuego rompe drasticamente, dando um uso inesperado para uma ilha da Baía de Guanabara na década de 1960.
\end{abstract}

Palavras-Chave: Baía de Guanabara; Luz del Fuego; narrativa feminina; representação.

\begin{abstract}
The paper discusses the landscape of Guanabara's Bay through David Neves' film, Luz del Fuego (1982). Starting from the understanding that the Bay conforms a collective memory space that occurs not only in the past, but also in the present, we seek to understand the current relationship of the population of Rio de Janeiro with the Bay. Denis Cosgrove (1989) assists us by identifying multiple types of symbolic landscapes within them: dominant culture landscape and alternative landscape. The analyzed film tells the story of the dancer Dora Vivacqua, an important woman for female liberation in Rio de Janeiro. And has a particular look on the Bay, housing and scene of the death of the protagonist. During the film narrative it is necessary to look not only at the landscape optics of the dominant culture, but also at the alternative landscape, described by Cosgrove, as well as a gender problem, where there is often the erasure of female narratives. Women are part of the culture excluded from the public landscape, since women's use of the landscape has long been the domestic landscape. What Luz del Fuego breaks dramatically, giving unexpected use to an island of Guanabara`s Bay in the 1960s.
\end{abstract}

Key-Words: Guanabara`s Bay; Luz del Fuego; female narrative; representation. 


\section{Introdução}

Partimos do pressuposto que a paisagem está em constante transformação no espaço-tempo e um dos principais palcos dessa modificação na cidade do Rio de Janeiro e em sua Região Metropolitana é a Baía de Guanabara. Parte muito importante tanto histórica quanto ambientalmente, a Baía, até hoje é um dos acessos principais da cidade. Entretanto, acabou negligenciada pelo crescimento urbano a partir da segunda metade do século XX. Atualmente, conta com tráfego de navios, barcas de travessias, aeroportos, plataformas de petróleo e pesquisas, além da concentração da poluição proveniente do esgoto sem tratamento despejado em suas águas.

A relevância dessas águas para a cidade pode ser atribuída a diversos fatores como: a presença das aldeias de Tamoios (Tupinambás) e Temiminós (Maracajás), a chegada dos portugueses no período da colonização, os navios negreiros com pessoas escravizadas, a importância do porto de Maria Angu na Zona Norte, a presença de patrimônios coloniais e modernos à beira-mar etc. Dessa forma podemos perceber a Baía de Guanabara como um lugar da memória coletiva, que não deriva de fatos lineares e que depende de uma comunidade afetiva (HALBWACHS, 2006 [1950]). Essas reflexões evidenciam que a memória é uma construção realizada por um grupo de indivíduos e que pode ser reconstruída. E um dos papéis das narrativas visuais é recontar histórias e ressignificar a memória.

Um dos conceitos-chave para discussão desse trabalho é o de representação, entendemos aqui como sendo o significado atribuído a uma linguagem, no caso a paisagem (HALL, 2016). Partimos também do pressuposto que a Baía é um lugar simbólico, onde várias culturas se encontram, podendo gerar conflitos. A geógrafa Doreen Massey define lugar não como possuidor de uma identidade única, mas múltiplas, lugares não estão congelados no tempo, mas são processos. Sendo assim, podem ser ressignificados como as memórias.

Durante o processo de pesquisa, o trabalho conheceu diversas paisagens da Baía de Guanabara. Em meio às descobertas de representações da Baía, encontram-se Luz del Fuego como uma mulher de grande importância para o Rio de Janeiro e pouco estudada. Dessa forma o presente trabalho se propõe a discutir a representação da paisagem da Baía de Guanabara a partir de uma narrativa visual, o filme Luz del Fuego (1982), de David Neves, em uma estrutura dialética da própria dançarina Luz del Fuego (Dora Vivacqua) na Baía de Guanabara até o ano de sua morte em 1967 e sua representação sob o olhar do diretor em 1982.

\section{Paisagem simbólica}

A paisagem da cidade é um elemento que geralmente está no imaginário coletivo de seus habitantes. Tal reflexão está expressa em Cidades Invisíveis de Ítalo Calvino (2003), quando o imaginário de cidade se constrói através de narrativas de um viajante. Entretanto a relação do imaginário e do real pode ser uma linha tênue, por isso é importante então entender a construção da paisagem propriamente dita.

Historicamente, o estudo da paisagem passa por diversas vertentes, o significado da palavra como recorte ou espaço limitado observável, aparece no Renascimento (século XIV), indicando uma nova relação entre o ambiente e os seres humanos. Na modernidade os aspectos culturais de uma sociedade passam a ser um elemento que age sobre o meio natural, assim o geógrafo Carl Sauer (1998) define a paisagem cultural:

As ações do homem se expressam por si mesmas na paisagem cultural. Pode haver uma sucessão dessa paisagem com uma sucessão de culturas. Elas derivam em cada caso da paisagem natural, com o homem expressando seu lugar na natureza como um agente distinto de modificação. De especial importância é aquele clímax de cultura que chamamos de civilização. A paisagem cultural então é sujeita a mudança pelo desenvolvimento da cultura ou pela substituição de culturas (SAUER, 1998, p. 43).

Após a década de 1970, uma outra corrente sobre a paisagem vai obtendo mais espaço. 0 conceito de paisagem abordado neste trabalho parte do geógrafo Denis Cosgrove (1989), que identifica múltiplas categorias de paisagens geográficas ou culturais, sua denominação para as 
paisagens simbólicas abarcam a paisagem da cultura dominante e paisagem alternativa. Vamos tomar como ponto de partida essa dualidade.

Para Cosgrove, a cultura dominante estabelece uma relação de poder sobre um outro grupo e está baseada no controle dos meios de vida. Esse grupo dominante determina onde estão as forças de uma comunidade. A paisagem está atrelada aos seus símbolos e significados e compreendê-la permitirá refletir sobre o nosso lugar nesse espaço. $O$ autor irá dizer que as paisagens alternativas são menos visíveis. Entretanto essa lógica pode ser invertida dependendo da escala da observação. Cosgrove irá destrinchar as paisagens alternativas em três momentos: residuais, quando se perde seu significado original; emergentes, quando possuem pouca permanência sobre a paisagem, porém provocam futuros alternativos; e excluídas, a narrativa não contada e negligenciada. Essa última classificação nos será útil para compreender o apagamento de certas memórias da Baía.

As reflexões de Cosgrove sobre a paisagem excluída, mostram-se como um problema de gênero, onde muitas vezes existe o apagamento das narrativas femininas.

Em geral, as mulheres representam a maior cultura singular excluída, pelo menos no que tange ao impacto sobre a paisagem pública. (...) A organização e o uso do espaço pelas mulheres pressupõem um conjunto muito diferente de significados simbólicos que aqueles dos homens, e na última década foram feitos estudos iniciais para revelar o significado das diferenças de sexo na atribuição e reprodução do simbolismo na paisagem (COSGROVE, 1989).

Ao longo do processo histórico, as mulheres estavam presentes na paisagem doméstica e não tinham grande participação na paisagem pública da cidade. Por sua vez, suas visões e representações não recebiam devida atenção. Um fato que corrobora para que as mulheres tenham adquirido algum espaço na cidade, ocorre a partir de 1932 quando foi instituído o direito ao voto feminino para mulheres casadas e perante a autorização do marido. Atualmente, mesmo com o direito pleno do voto, ainda assim sofrem com a invisibilidade de suas vivências públicas. A responsabilidade pelo conteúdo e forma das contribuições é exclusiva dos autores.

\section{Luz del Fuego na paisagem real}

Para entender Luz del Fuego no filme de David Neves é importante saber um pouco mais sobre essa personagem real. De acordo com sua biografia romanceada escrita em 1994 (AGOSTINHO, PAULA, BRANDÃO, 1994) Dora Vivacqua nasceu em 1917 em Cachoeiro de Itapemirim, Espírito Santo. Foi integrante de uma família conservadora de grande importância descendentes de italianos. Filha de Etelvina Souza Monteiro Vivacqua e José Antônio Vivacqua, juntamente com dezessete irmãos, mudou-se ainda criança para Belo Horizonte, Minas Gerais. Tem contato com diversos intelectuais como Carlos Drummond de Andrade.

Quando mais velha criou um grande fascínio pelo Rio de Janeiro. Morou com uma de suas irmãs mas em uma situação de assédio pelo próprio cunhado, é mandada a um manicômio. Lugar esse que é retirada por um de seus irmãos, porém é internada outra vez pois sua família não aceitava seu comportamento e a caracterizava como uma mulher louca. As autoras de sua biografia romanceada descrevem o momento que justificou sua internação pela segunda vez:

O rapaz recua alguns passos e fica imóvel. O desejo dando lugar ao medo. Além das três folhas de parreira presas nos seios e no púbis, Dora traz nos braços duas cobras-cipós, enroladas como se fossem braceletes. Ela acha graça nos olhos arregalados do rapaz (...) (AGOSTINHO, PAULA, BRANDÃO, 1994, p. 124).

Pouco antes de completar sua maioridade foge para o Rio de Janeiro, em busca de uma vida livre. Por volta de 1942 inicia uma carreira artística como Luz Divina, posteriormente muda seu nome artístico para Luz del Fuego. Dança em circos com uma jiboia e encanta o público. Em 1949 funda o Partido Naturalista Brasileiro com o slogan "Menos roupa e mais pão!", porém o partido não é registrado, o porquê mais tarde vamos saber, que um de seus irmãos põe fim nos documentos. Posteriormente, Luz consegue uma autorização da Marinha do Brasil para viver na ilha Tapuama de Dentro e a rebatiza de Ilha do Sol. É lá que funda o Clube Naturalista Brasileiro, o primeiro na América Latina. Mantinha um rígido controle de acesso e permanência distinguindo naturalismo de 
libertinagem. A llha do Sol atraiu personalidades do cinema internacional, como Ava Gardner e Brigitte Bardot.

\section{Luz del Fuego na tela imaginária}

Devemos ter em mente que uma representação cinematográfica é uma das visões sobre um determinado objeto. Neste caso o filme de David Neves possui um olhar particular tanto sobre Luz del Fuego quanto sobre a Baía de Guanabara, moradia e cenário da morte da protagonista após se relacionar com um importante senador da década de 1950, João Gaspar. No filme, Luz Del Fuego é interpretada por Lucélia Santos. Na narrativa do diretor, já adulta e no teatro de revista, ela participa de um coro de vedetes e é presa por atentado ao pudor por dançar nua com uma cobra. No auge da fama Luz vende sua mansão, abandona o teatro, se muda e compra a llha do Sol, no interior da Baía, com a ideia de criar um paraíso ecológico naturalista e a primeira praia de nudismo do Rio de Janeiro. Porém Luz del Fuego é misteriosamente assassinada.

A ideia do diretor foi dividir o filme em duas partes: a primeira em tom de chanchada, com certo humor e ar burlesco, e o segundo momento com um olhar mais poético, tendo foco na relação da protagonista com a própria Baía. Neves cria uma espécie de biografia-ficção traduzida numa narrativa fílmica. Luz del Fuego e a Baía são retratadas deslocadas, e fora de uma lógica de pertencimento, ambas são negligenciadas nesse momento da década de 1960 . Porém juntas são resistências.

Baseado em fatos reais da vida de dançarina, atriz e performance, Dora Vivacqua, defendeu o divórcio, a mulher e o nudismo. Com o fim do governo de Juscelino Kubitschek e início do anticomunismo, Luz é forçada a fechar seu clube em 1967, pois fazia diversas denúncias sobre pescadores em atividades não ecológicas. A artista é assassinada e seu corpo encontrado alguns meses depois na própria Baía. Alguns fatos da biografia de Dora são reinterpretados pelo diretor, como seus relacionamentos e sua dependência para o sucesso.

A narrativa fílmica é importante para a construção da paisagem e da própria imagem de Luz. Como vimos anteriormente pelo autor Cosgrove, a paisagem excluída, também é um problema de gênero. As mulheres fazem parte da parcela da cultura excluída da paisagem pública, já que o uso da paisagem pela mulher por muito tempo se deu pela paisagem doméstica, o que Luz del Fuego rompe drásticamente. Os significados simbólicos das mulheres sobre a paisagem são diferentes da cultura dominante formada por homens brancos.

Neste caso fílmico, a narrativa de Luz, apesar de intermediada por David Neves, é uma obra que retrata a importância da personagem para as lutas feministas brasileiras. O fato do diretor ser um homem irá causar certas interpretações quanto à história de Dora, como por exemplo seus caprichos atendidos por seus amantes. Entretanto, podemos observar na biografia de Luz del Fuego e seus próprios livros, sua força como mulher independente e à frente do seu tempo, contribuindo para representações de mulheres que buscam igualdade e liberdade.

As leituras do filme evidenciam certos aspectos da personalidade de Luz, como uma mulher rebelde que andava nua a todo momento. Porém a nudez de Luz del Fuego existia em um propósito ideológico e não em um aspecto moralista. O tom do filme ronda até mesmo algumas obras de Nelson Rodrigues, protagonizado por Lucélia Santos em Bonitinha mas ordinária, um ano antes desse filme.

\section{Visões e representações}

Retomando a leitura de autores como Ítalo Calvino que permeiam o imaginário com suas visões de cidades e reinterpretação da paisagem, em uma espécie de relatos de viajantes, a construção da paisagem das cidades descritas em Cidades Invisíveis passam pelo imaginário coletivo, assim como a construção da Baía de Guanabara da década de 1960 através do filme de David Neves. O diretor irá traduzir o olhar sensível de Luz del Fuego sobre a Baía de Guanabara, que por muito tempo foi negligenciado pela história dominante. 
A relação que a história dominante e a visão de um diretor homem sobre uma história de luta feminina perpassa pelo perigo da história única, que silencia narrativas em prol de outras. Chimamanda Ngozi Adichie (2009) descreve esse processo como uma história que cria estereótipos, que por sua vez, são incompletos e construídos socialmente, porém por algum tempo são considerados verdades absolutas. Luz coloca em evidência uma ilha da Baía de Guanabara dando um uso inesperado, sendo resistência na década de 1960, em um momento pouco evidente sobre a luta feminina. A proposta de pensarmos uma perspectiva feminina da Baía contribui dessa maneira para combater a ideia de que tal paisagem sirva apenas de acesso ao Rio de Janeiro, como historicamente percebemos nos relatos da invasão portuguesa em terras indígenas no início do processo de colonização.

A localização da llha do Sol é fundamental para Luz del Fuego conseguir uma certa liberdade, já que a ilha está mais adentro da Baía, em uma área mais negligenciada. Em um momento quando as praias da orla estão no cotidiano da população, Dora compra a ilha entendendo o fundo da Baía como libertação. É nesse momento também que começa a perceber a degradação de suas águas. Enquanto figura de resistência feminina, impõe sua permanência em um espaço que na lógica da paisagem da cultura dominante não poderia ser seu. Vale ressaltar que, porém, que as filmagens se realizaram na llha dos Lobos, aos arredores da llha de Paquetá, Rio de Janeiro, provavelmente pela logística das filmagens e autorizações. Podemos observar tal relação na figura a seguir.

Figura 1: Localização Ilha dos Lobos e Ilha do Sol.

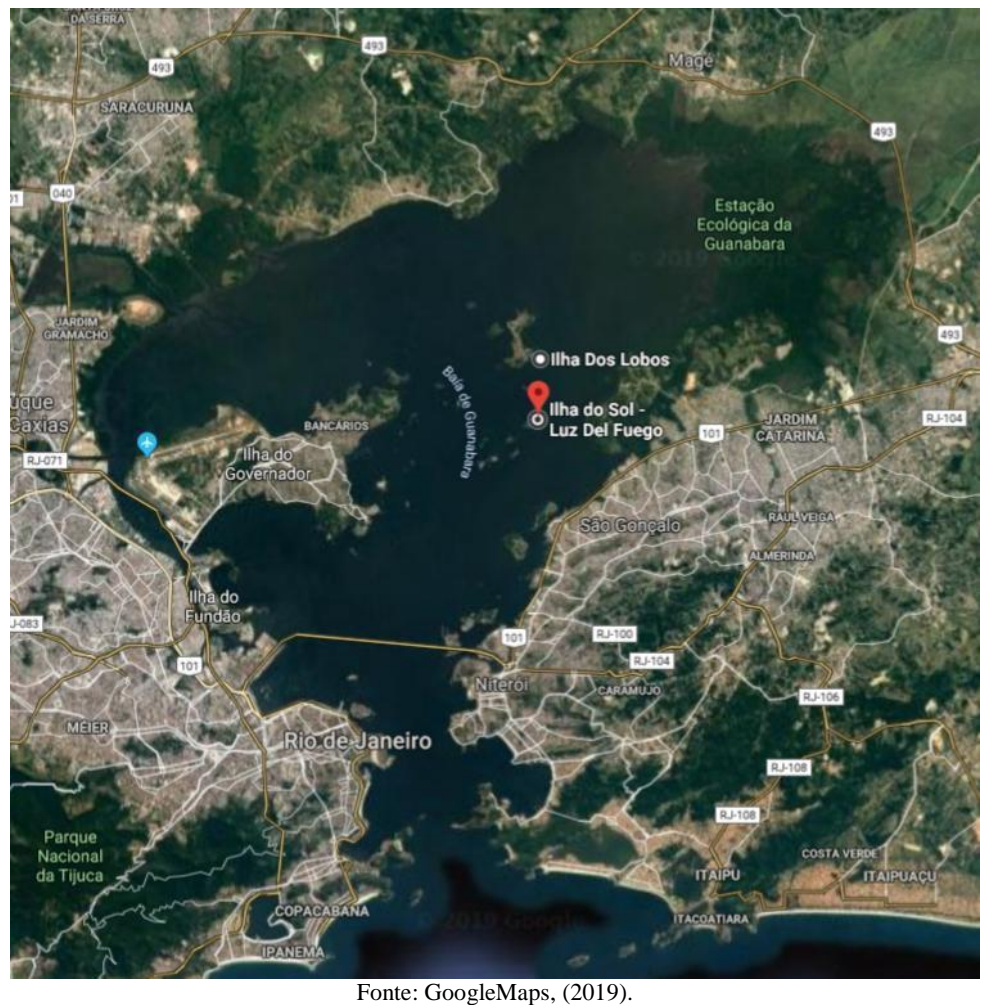

\section{Narrativa fílmica: a imagem-movimento}

O diretor David Neves (1938-1994) é considerado um atuante do Cinema Novo, movimento cinematográfico brasileiro, que se opôs ao cinema tradicional brasileiro de estilo "hollywoodiano". Luz del Fuego pode ser considerado uma evocação da memória brasileira nesse sentido, mesmo sendo feito após o período de seu auge.

As reflexões acerca da temática do cinema como representação da paisagem, neste trabalho, partiram da conceituação de imagem-movimento e imagem-tempo apresentada pelo filósofo francês Gilles Deleuze (2018), com base nas teorias de Henri Bergson. Deleuze irá mostrar que no cinema contemporâneo existe uma narrativa que não se constrói de forma linear, mas que é 
tratada como uma sucessão de fragmentos rizomáticos, que contêm o tempo passado e presente. Por sua vez, essa narrativa fílmica possui uma relação direta com a memória.

As ideias de Bergson relacionadas ao movimento, vistas por Deleuze, podem ser interpretadas dentro da área do cinema como a própria montagem, por exemplo. Permite, assim, duas perspectivas de se pensar a imagem movimento:

\begin{abstract}
A imagem movimento tem duas faces, uma em relação a objetos cuja posição ela faz variar, a outra em relação a um todo cuja mudança absoluta ela exprime. As posições estão no espaço, mas o todo que muda está no tempo. Se assimilarmos a imagem movimento ao plano, chamaremos de enquadramento à primeira face do plano, voltada para os objetos, e de montagem à outra face, voltada para o todo (DELEUZE, 2009, p. 48).
\end{abstract}

Logo, podemos perceber a ideia de tempo, resultante da análise do movimento, com a noção de que o todo que muda está no tempo. Observamos então alguns enquadramentos do filme, como exemplo na figura 2, Luz del Fuego aparece nua com uma cobra enrolada em seu corpo acenando para os visitantes da ilha. A personagem é performática até mesmo longe dos olhos do grande público, e continua teatral na sua morada, o que pode caracterizar que Luz del Fuego não é o alter ego de Dora mas seu próprio reconhecimento quanto mulher livre.

Já no quadro da figura 3 a Baía aparece melancólica com o bater em retirada dos pássaros. Em algumas passagens do filme, o olhar do diretor remete a beleza natural da própria Baía. As águas da Guanabara aparecem como lugar de contemplação, berçário, reprodução e resguardo, associação direta com a construção da imagem da mulher que nossa sociedade possui. A imagem da mulher acolhedora, da figura da mãe. Remetendo ao próprio nome do lugar, Guanabara em tupi, seio do mar.

Na figura 4 Luz mergulha nua e livre nas águas da Guanabara. É o momento que o real se funde com o imaginário, fogo e água estão em um único quadro. A própria Luz del Fuego associava essa dualidade ao seu antigo nome, Vivacqua. São três momentos distintos da relação de Luz com a Baía. Porém as três são imagens de libertação e exploração da imagem do feminino, até mesmo na imagem simbólica dos pássaros.

Figura 2: Luz del Fuego.

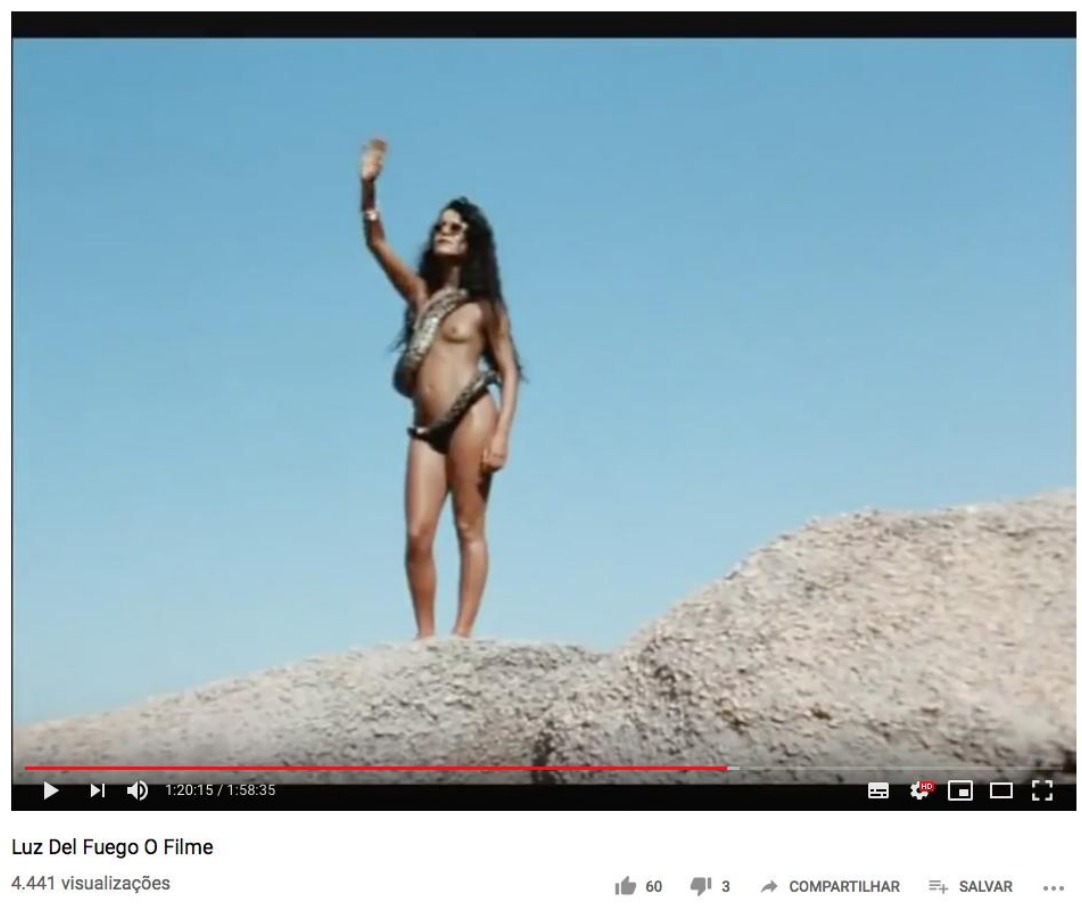

Fonte: filme "Luz del Fuego", (1982). 
Figura 3: A Baía.

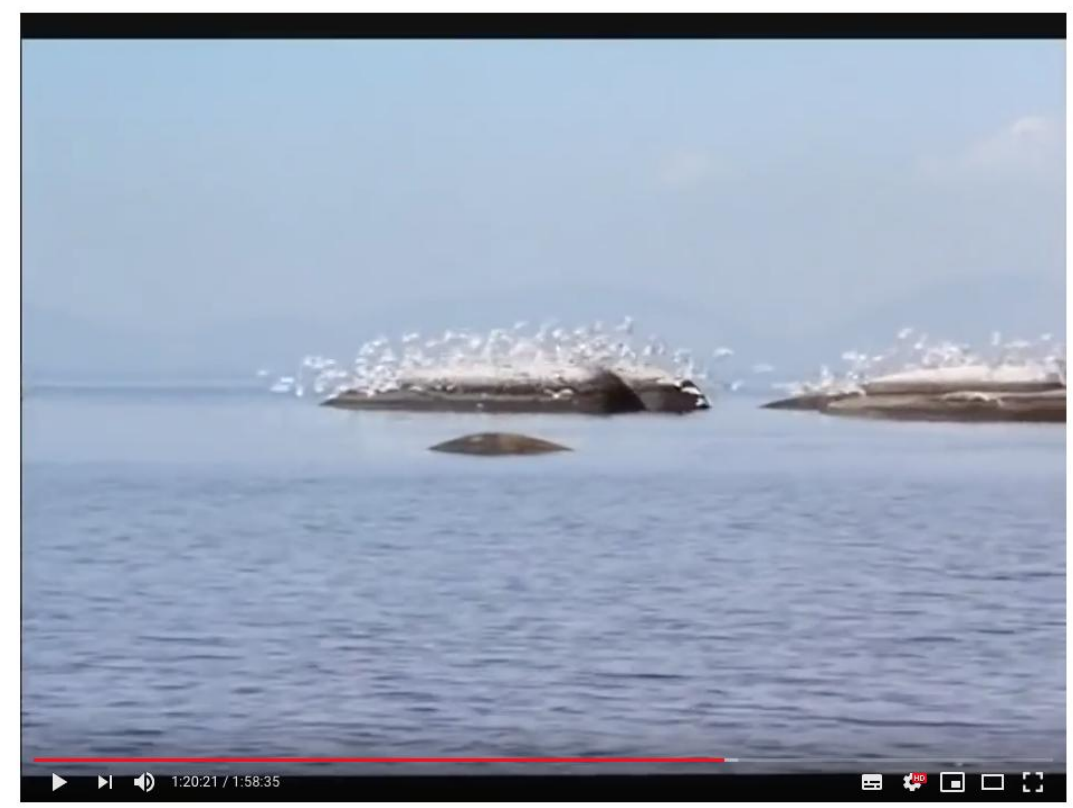

Luz Del Fuego 0 Filme

4.441 visualizações

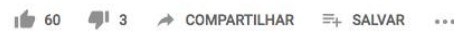

Fonte: filme "Luz del Fuego", (1982).

Figura 4: Em continuidade da sequência, Luz del Fuego, mergulha na Baía, nua e livre.

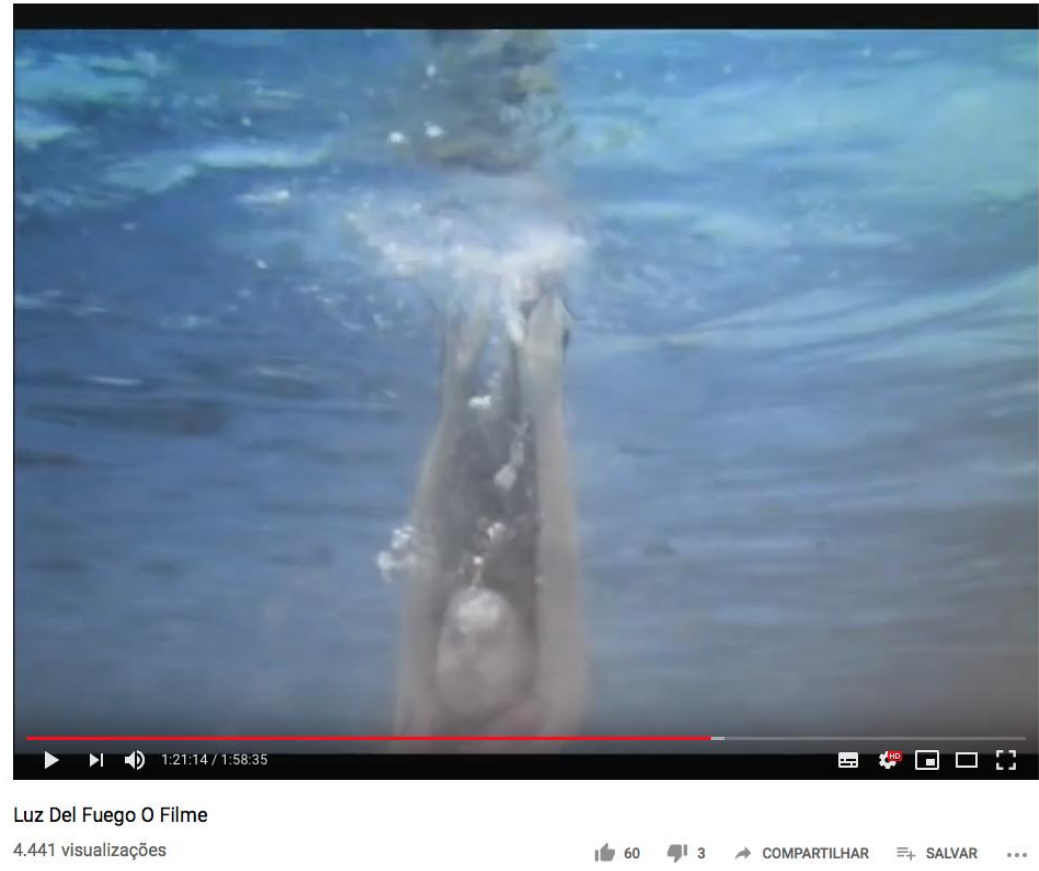

Fonte: filme "Luz del Fuego", (1982).

\section{Cidade-análoga}

Esta análise, além da experimentação sobre a imagem, é uma tentativa de construção de um presente que reforça a memória do lugar. Sob o âmbito do urbanismo, o arquiteto italiano Aldo Rossi contribui com seu livro $A$ arquitetura da cidade (1966), quando fala da memória coletiva 
apresentada por Maurice Halbwachs (1925). Rossi faz uma associação direta, assim como Halbwachs, da lembrança com o contexto social que está inserida, podendo assim reconstruir a memória, que deixa de ter apenas a dimensão individual, compreendendo que nenhuma lembrança pode coexistir isolada de um grupo social.

Aldo Rossi também contribui para esse trabalho com seu conceito de cidade-análoga, onde discute a imagem da cidade, entendendo sua extensão como uma série de colagens históricas. Ele questiona se a imagem da cidade que nós temos, seria realmente o que a cidade é. Como breve interpretação do conceito, tem-se o quadro Capriccio con edifici palladiani (1755-1759), de Canaletto (figura 5), onde uma vista de uma paisagem tipicamente veneziana está montada com obras de Palladio realizadas em Vicenza unidas pelo projeto não realizado para a Ponte do Rialto. Cidade análoga parte de um método de estudo de cidades por meio da analogia do lugar, com elementos marcantes que podem caracterizar na memória coletiva o que seria aquele espaço.

Figura 5: Capriccio con edifici palladiani.

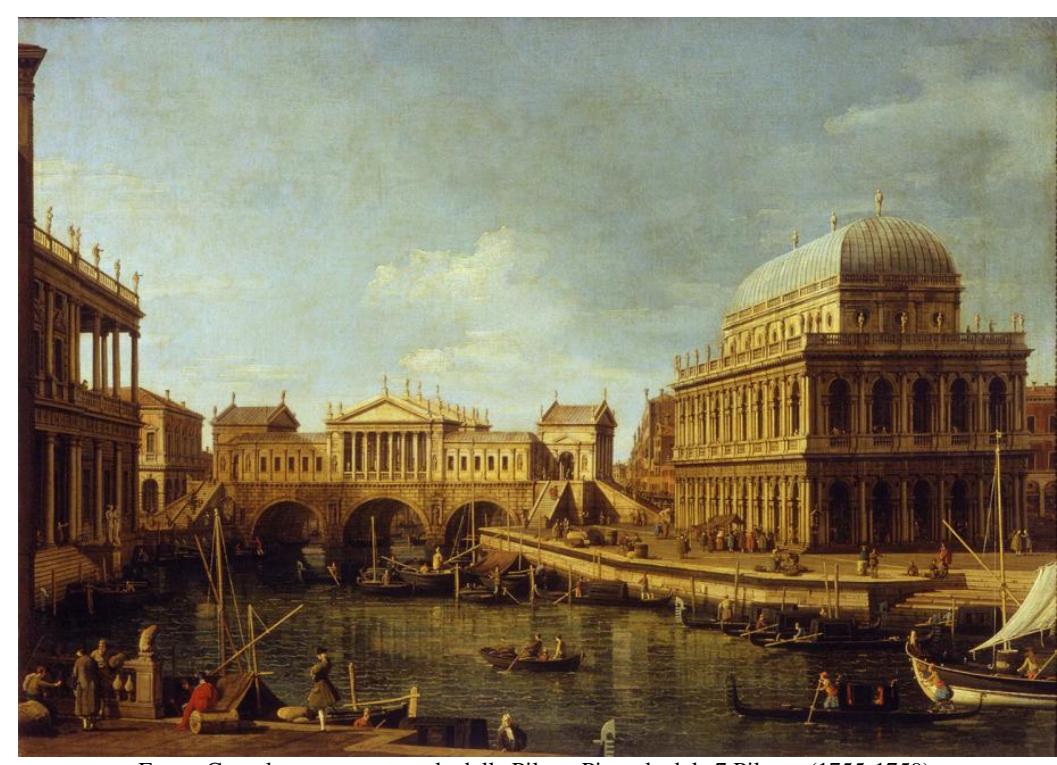

Fonte: Complesso monumentale della Pilotta Piazzale dela 7 Pilotta, (1755-1759).

Tanto a imagem-análoga que Aldo Rossi analisa, tanto quanto o cartão postal do Rio de Janeiro, não demonstram o que realmente é a representação da cidade. São retratos genéricos e simplificados de uma memória espacial. O objetivo desse conceito é problematizar a representação da cidade, e nos serve para buscar aonde as memórias invisíveis estão nessa paisagem dominante. Luz del Fuego se assume na paisagem na presença da llha do Sol. E nos mostra que habitar a paisagem é pertencê-la.

\section{Visibilidades e invisibilidades}

As reflexões sobre as representações da paisagem nos ajudam a perceber os limites ou não limites sobre o que é visível e o que é negligenciado, qual história é contada e porque uma é escolhida pela outra. Para subverter a lógica dominante Suely Rolnik e Félix Guattari (1996) nos trazem a micropolítica, que é definida como estratégias da economia do desejo no campo social. Os autores afirmam que o sujeito está o tempo todo submetido à forças externas, com isso ele se modifica, porém estamos buscando um equilíbrio e esse equilíbrio é encontrado através dos nossos desejos. As investigações giram em torno desses desejos e da identidade do sujeito.

Os autores discorrem sobre o que eles chamaram em seu livro de revoluções moleculares, com o atrevimento do singularizar. Assim como Gilles Deleuze, Guattari muitas vezes busca suas metáforas e analogias na natureza, lidando aqui com o indivíduo como molécula. Eles vão defender que o sujeito construa seus próprios tipos de referências práticas e teóricas, sem ficar dependendo do poder global. "É preciso que cada um se afirme na posição singular que ocupa; a faça viver, que a articule com outros processos de singularização e que resista a todos os 
empreendimentos de nivelação de subjetividade" (GUATARRI e ROLNIK, 1996, p. 50). Com essa frase os autores afirmam que é preciso entender as particularidades de nós mesmos na luta contra o sujeito modelo tanto colocado no modernismo. Essa reflexão nos ajuda a perceber a importância das pequenas "revoluções" que Luz del Fuego provocou.

Os debates aqui inseridos dialogam diretamente com a situação de disputa da paisagem da Baía de Guanabara, por ora com enobrecimento da orla através de alguns bairros como Centro/Zona Sul da cidade do Rio de Janeiro, ou Icaraí, São Francisco e Charitas em Niterói; e ora com a negligência frente as demais margens da Baía, como os municípios de Magé, Guapimirim, São Gonçalo, Duque de Caxias, além da Zona Norte do Rio, com uma população de poder econômico mais baixo. Em um momento com uma lógica econômica e turística, e outro por um abandono cultural. É evidente que esses cenários não são opostos em si na escala micro, mesmo dentro dos bairros negligenciados há disputas na paisagem a todo momento. $O$ território se estabelece nas disputas, como então seria o equilíbrio dessa paisagem? Talvez a resposta esteja no tempo e não no espaço, em alguns momentos temporais esses mesmos territórios são ressignificados.

Confrontar a desigualdade no Brasil é de grande complexidade, pois tal, atua de forma estruturante em nossa sociedade, afetando inclusive o espaço urbano. Como exemplo os grandes investimentos do próprio poder público em turismo em áreas selecionadas da cidade. Sob essa lógica, foi desenvolvido um ensaio de uma imagem-análoga da Baía, a figura 6, mostra essa cidade do Rio de Janeiro que é vendida. Uma paisagem que torna invisível todas as memórias alternativas excluídas da Baía. Defendemos que a Baía de Guanabara é muito mais do que o Pão de Açúcar.

Figura 6: Panorama através de fragmentos da Baía de Guanabara.
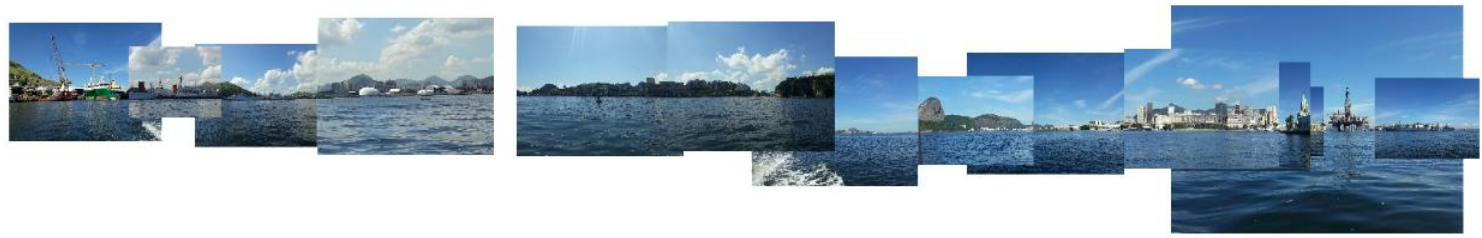

Fonte: arquivo pessoal da autora, (2019)

Em resumo, esse artigo procurou interpretar uma representação da Baía de Guanabara sob a lente do filme de Luz del Fuego, através da imagem-movimento de Gilles Deleuze, pensando os enquadramentos como paisagens. Dessa forma os conceitos de paisagem do geógrafo Denis Cosgrove e cidade-análoga do arquiteto Aldo Rossi, juntamente com a representação por Stuart Hall e Doreen Massey completam o quadro teórico analítico.

As conclusões parciais deste trabalho são referentes à negligência da paisagem da Baía de Guanabara, e principalmente a invisibilização de narrativas alternativas. Luz del Fuego é apagada da memória da Baía e retirada violentamente de seu território. O filme de David Neves tenta recontar essa história, mas pouco explora a força de Luz e da própria Baía de Guanabara, deixando lacunas que precisam ser cada vez mais preenchidas com representações complexas da paisagem e de figuras históricas que merecem ser enaltecidas. Associar a personagem à Baía de Guanabara é entrelaçar a magnitude de ambas no processo de descortinar o que é invisível.

\section{Referências}

AGOSTINHO, Cristina; PAULA, Branca de; BRANDÃO, Maria do Carmo. Uma biografia / Luz del Fuego: a bailarina do povo. Rio de Janeiro: Best Seller, 1994.

CALVINO, Italo. As Cidades Invisíveis. São Paulo: Folha, 2003.

CARVALHO, Anna Maria Fausto Monteiro de. A Baía de Guanabara Os itinerários da memória. São Paulo: Revista USP, 1996. 
CORRÊA, Armando Magalhães. (Org.); VIEIRA, Antônio Carlos Pinto. A Guanabara como natureza: Águas Cariocas. 1를 $\mathrm{ed}$ - Rio de Janeiro: Outras Letras, 2016.

COSGROVE, Denis. A geografia está em toda parte: cultura e simbolismo nas paisagens humanas. In: Corrêa, Roberto Lobato e Rosendahl, Zeny (orgs.). Paisagem, Tempo e Cultura.Rio de Janeiro, EdUERJ, 1998.

DELEUZE, Gilles. Cinema 1 - A imagem-movimento / Gilles Deleuze; tradução de Stella Senra São Paulo: Editora 34, 2018 (1를 edição).

GUATTARI, Félix, ROLNIK, Sueli. Micropolíticas: cartografias do desejo. Petrópolis: Vozes, 1996. [1986]. (6. Revoluções moleculares: o atrevimento de singularizar. Pp. 45-65)

HALBWACHS, Maurice. A memória coletiva. São Paulo: Ed. Centauro, 2006.

HALL, Stuart. Cultura e representação. Rio de Janeiro: PUC, 2016.

LIMA, Edvaldo Pereira. et al. retratos da baía. Rio de Janeiro: FAPERJ, 1994.

MASSEY, Doreen B. Pelo espaço: uma nova política da espacialidade/ Doreen Massey; tradução Hilda Pareto Maciel, Rogério Haesbaert. - Rio de Janeiro: Bertrand Brasil, 2008.

MESENTIER, Leonardo Marques de; LIMA, Evelyn Furquim. A Paisagem da Baía de Guanabara: patrimônio, segregação e desenvolvimento. Rio de Janeiro. XV Seminário de História da Cidade e do Urbanismo, 2018.

ROSSI, Aldo. A arquitetura da cidade. Tradução de Eduardo Brandão. $2^{\underline{a}}$ ed. São Paulo: Martins Fontes, 2001.

Uma arquitetura analógica. In: NESBITT, Kate (Org.). Uma nova agenda para a arquitetura: antologia teórica 1965-1995. 2. ed. São Paulo: Cosac Naify, 2008. p. 379-384.

SARTHOU, Carlos. Passado e Presente da Baía da Guanabara. Rio de Janeiro: Livraria Freitas Bastos S.A., 1964.

SAUER, Carl. A morfologia da paisagem. In: Paisagem, Tempo e Cultura. CORRÊA, R.L.; ROSENDAHL, Z. (orgs.). Rio de Janeiro: EDUERJ, 1998 (1925).

LUZ Del Fuego - O Filme. Direção: David Neves. Rio de Janeiro: (produtora), 1982. Disponível em: $<$ https://www.youtube.com/watch?v=mn-uv0dI9nA >. Acesso em: 24/06/2019.

TED Chimamanda Ngozi Adichie e o perigo da história única. Disponível em:

$<$ https://www.ted.com/talks/chimamanda adichie the danger_of a single story?language=pt-br t-1109987>. Acesso em: 10/08/2019. 